TIERS Information Technology Journal

Vol.2, No.1, Juni 2021, pp. 31 36

ISSN: 2723-4541 / E-ISSN: 2723-4533

DOI: $10.38043 /$ tiers.v2i 2.3311

\title{
Arsitektur Internet of Things (IoT) Berskala Industri dengan fitur Over The Air Update
}

\author{
${ }^{1}$ I Gusti Ngurah Darma Paramartha, I Nyoman Hary Kurniawan², Gde Brahupadhya Subiksa ${ }^{3}$, \\ Ayu Satya Kartika ${ }^{4}$ \\ ${ }^{1234}$ Program Studi Teknologi Informasi, Universitas Pendidikan Nasional, Bali
}

\begin{abstract}
Internet of Things (IoT) devices that are implemented in many places can experience changes in the form of firmware updates. Firmware updates on an Internet of Things (IoT) device are usually done by taking the Internet of Things (IoT) device, then connecting it to a computer using a USB cable, then updating the firmware on the Internet of Things (IoT) device and returning the device to its place. With the Over The Air (OTA) update method, firmware updates on Internet of Things (IoT) devices can be done without having to come to the place of the Internet of Things (IoT) device. So that when there is a firmware update, Internet of Things (IoT) devices can directly download and install themselves without human intervention. Over The Air firmware update is loading the firmware build from Arduino IDE on Internet of Things (IoT) devices using a Wi-Fi network interface, in this study the microcontroller used is ESP32. The platform used is ThingsBoard which is open-source. This ThingsBoard platform makes it possible to upload and distribute Over The Air (SOTA) updates to Internet of Things (IoT) devices. Administrators on Thingsboard can upload firmware or software packages to the Over The Air (OTA) repository, then assign them to an Internet of Things (IoT) Device Profile or Device. ThingsBoard will notify devices of available updates and provide a protocol-specific API for downloading firmware. This ThingsBoard platform will track the update status and save the update history. This update process can be monitored using the dashboard. The ThingsBoard platform can be used for free or paid depending on the needs of the Internet of Things (IoT) project. Not only that, the ThingsBoard platform is equipped with an access token-based security system, MQTT basic credentials, and X.509 certificate-based authentication.
\end{abstract}

Keywords: Internet of Things, Firmware update, Over The Air, ThingsBoard

\section{ABSTRAK}

Perangkat Internet of Things(IoT) yang diimplementasikan di banyak tempat dapat mengalami perubahan berupa update firmware. Update firmware pada sebuah perangkat Internet of Things (IoT) biasanya dilakukan dengan cara mengambil perangkat Internet of Things(IoT), lalu menghubungkan ke komputer menggunakan kabel USB, selanjutnya melakukan update firmware terhadap perangkat Internet of Things(IoT) dan mengembalikan perangkat ke tempat. Dengan adanya metode pembaruan Over The Air (OTA), pembaruan firmware pada perangkat Internet of Things(IoT) dapat dilakukan tanpa harus datang ke tempat perangkat Internet of Things (IoT) tersebut. Sehingga ketika terdapat pembaruan firmware, perangkat Internet of Things (IoT) dapat langsung melakukan download dan menginstall sendiri tanpa intervasi manusia. Over The Air update firmware adalah memuat firmware hasil build dari Arduino IDE pada perangkat Internet of Things (IoT) menggunakan antar muka jaringan Wi-Fi, pada penelitian ini perangkat mikrokontroller yang digunakan yaitu ESP32. Platform yang digunakan yaitu ThingsBoard yang bersifat open-source. Platfrom ThingsBoard ini memungkinkan untuk mengunggah dan mendistribusikan pembaruan Over The Air (OTA) ke perangkat Internet of Things (IoT). Administrator pada Thingsboard dapat mengunggah firmware atau paket perangkat lunak ke repositori Over The Air (OTA), lalu menetapkannya ke Profil Perangkat atau Perangkat Internet of Things (IoT). ThingsBoard akan memberi tahu perangkat tentang pembaharuan yang tersedia dan menyediakan API khusus protokol untuk mengunduh firmware. Platform ThingsBoard ini akan melacak status pembaruan dan menyimpan riwayat pembaruan. Proses pembaruan ini dapat dipantau menggunakan dashboard. Platform ThingsBoard ini bisa digunakan secara gratis maupun berbayar tergantung kebutuhan dari proyek Internet of Things(IoT). Bukan hanya itu saja platform ThingsBoard ini dilengkapi sistem keamanan berbasis token akses, MQTT basic credentials, dan Otentikasi berbasis sertifikat X.509

Kata kunci: Internet of Things, Firmware update, Over The Air, ThingsBoard. 


\section{Info Artikel}

\begin{tabular}{lll} 
Diterima Redaksi & $:$ & $01-11-2021$ \\
Selesai Revisi & $:$ & $01-12-2021$ \\
Diterbitkan Online & $:$ & $30-12-2021$ \\
\hline
\end{tabular}

This is an open access article under the $\underline{C C B Y-S A}$ license.

\section{Penulis Korespondensi:}

I Gusti Ngurah Darma Paramartha

Teknologi Informasi, Universitas Pendidikan Nasional,

Jalan Dewata Gg. Buntu No. 3, Sidakarya, 80224.

Email: hary242000@gmail.com

\section{PENDAHULUAN}

Pada tahun 2020, ada 35 miliar perangkat Internet of Things (IoT) dengan konektivitas dan berkomunikasi tanpa interaksi dengan manusia. Juniper Research memperkirakan pertumbuhan Internet of Things (IoT) yang ditera pkan setia p tahun akan menjadi 46 miliar pada tahun 2021 dan akan terus berta mbah. Perangkat Internet of Things (IoT) digunakan di berbagai tempat sering dianggap sebagai sistem yang tidak perlu mengubah requirements dan fungsinya. Namun, pada kenyataannya di mana perangkat Internet of Things (IoT) ini berjalan pasti akan berubah. Perubahan ini meliputi peruba han parameter yang terkait komunikasi dengan sistem lain atau pengguna, memperbaharui sistem, memperbaiki kesalahan, bisa masalah keamanan, yang dila porkan pengguna setelah perangkat IoT digunakan.

Berbagaijenis perubahan pada perangkat Internet of Things (IoT) dapat dilakukan dengan melakukan pembaharuan pada firmware, untuk melakukan pembaharuan firmware pada perangkat Internet of Things (IoT) harus keluar mengambil perangkat Internet of Things (IoT) tersebut, lalu menghubungkan ke computer, melakukan pembaharuan, dan mengembalikan perangkat Internet of Things ke tempat. Namun hal seperti ini tidak dapat terus dilakukan bagi perusahaan yang memiliki perangkat Internet of Things (IoT) di berbagai tempat, karena itu akan memakan banyak waktu dan kurang efektif.

Jika sistem perangkat Internet of Things (IoT) sudah dapat berkomunikasi melakui antamuka jaringan, hal ini bisa dimaanfatkan untuk menerapkan pembaruan firmware pada sistem Internet of Things (IoT) yang disebut dengan Over The Air (OTA). OTA juga diterapkan oleh perusahaan Tesla untuk mengirimkan pembaharuan firmware pada setiap kendaraan mereka dan para konsumen dapat mengatur pembaruan saat kendaraan dalam keadaan diparkir. Over The Air (OTA) merupakan proses memuat firmware hasil build dari Arduino IDE pada perangkat Internet of Things (IoT) menggunakan koneksijaringan Wi-Fi dari pada menggunakan kabel port serial. Pada penelitian ini perangkat mikrokontroller yang digunakan yaitu ESP32. Secara umum istilah OTA a dalah mekanisme pengunaan wireless untuk mengirim data, memperbaruifirmware a tau perangkat lunak ke perangkat mobile, sehingga pengguna tidak perlu mengakses fisik perangkat Internet of Things (IoT) untuk melakukan pembaharuan parameter,firmware atau software. Over The Air Update pada perangkat Internet of Things sudah bisa digunakan dengan platform ThingBoard yang bersifat open source. Platform ThingsBoard ini bisa digunakan secara gratis maupun berbayar tergantung kebutuhan dari proyek Internet of Things(IoT). Bukan hanya itu saja platform ThingsBoard ini dilengkapi sistem keamanan berbasis token akses, MQTT basic credentials, dan Otentikasi berbasis sertifikat X.509

Platfrom ThingsBoard ini memungkinkan untuk mengunggah dan mendistribusikan pembaruan Over The Air (OTA) ke perangkat Internet of Things (IoT). Administrator pada Thingsboard dapat mengunggah firmware atau paket perangkat lunak ke repositori Over The Air (OTA), lalu menetapkannya ke Profil Perangkat atau Perangkat Internet of Things (IoT). ThingsBoard akan memberi tahu perangkat tentang pembaharuan yang tersedia dan menyediakan API khusus protokol untuk mengunduh firmware. Platform ThingsBoard ini akan melacak status pembaruan dan menyimpan riwayat pembaruan. Proses pembaruan ini dapat dipantau menggunakan dashboard.Dashboard dari Thingsboard ini bisa berbasis website dan juga bisa berbasis aplikasi. Platform ThingsBoard relatif lebih mudah digunakan karena platform ThingsBoard merupakan bagian dari server sehingga tidak perlu membuat web server dari awal lagi. 


\section{METODE PENELITIAN}

Penerapan Over The Air Update firmware dengan menggunakan platform ThingsBoard berbasis website sebagaiinterface pengguna.

\subsection{Over The Air (OTA)}

Over The Air (OTA) merupakan proses memuat firmware pada perangkat Internet of Things (IoT) menggunakan koneksi jaringan Wi-Fi dari pada menggunakan kabel port serial. Secara umum istilah OTA ada lah mekanisme penguna an wireless untuk mengirim data, memperbaruifirmware atau perangkat lunak ke perangkat mobile, sehingga pengguna tidak perlu mengakses fisik perangkat Internet of Things (IoT) untuk melakukan pembaharuan parameter,firmware atau software.

\subsection{ThingsBoard}

ThingsBoard merupakan sebuat platform Internet of Things (IoT) yang bersifat opensource. ThingsBoard ini juga merupakan webserver yang dapat digunakan sebagai platform manajemen device, pengumpulan data, dan visualisasi data berbasis website. ThingsBoard juga memiliki dua fungsi utama yaitu sebagai broker dalam terminologi Internet of Things (core services) dan sebagai web presentation/penyaji data(web UI). Thingsboard memungkinkan pengguna untuk melakukan perancangan dan konfigurasi dashboard Internet of Things (IoT) yang dapat disesuaikan dengan kebutuhan dan keinginan pengguna. Dashboard perangkat di Thingsboard biasanya berisi widget yang memvisualisasikan data telemetri dari perangkat Internet of Things (IoT) yang berbeda. ThingsBaord juga mendukung enkripsi transport untuk protokol MQTT dan HTTP.

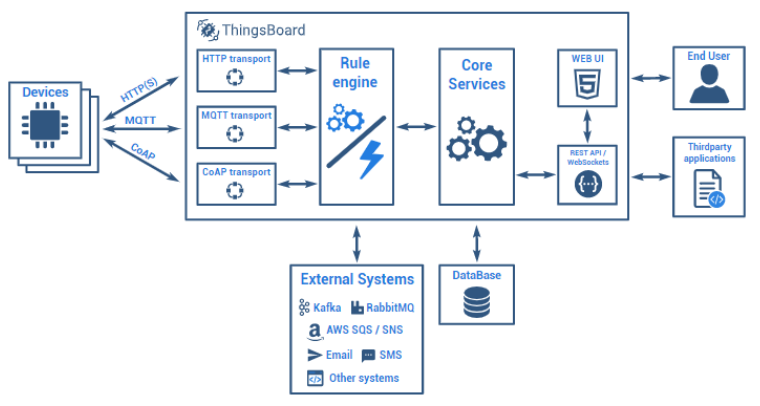

Gambar 1. Desain Arsitektur ThingsBoard

\subsection{Desain framework On The Air (OTA) pada platform ThingsBoard}

ThingsBoard memungkinkan untuk mengunggah dan mendistribusikan pembaruan Over The Air (OTA) ke perangkat. Administrator dapat mengunggah firmware a tau paket perangkat lunak ke repositori $O n$ The Air (OTA). Lalu dapat menetapkannya ke profile perangkat atau perangkat. ThingsBoard akan memberi tahu perangkat tentang pembaruan yang tersedia dan menyediakan API khusus protokol untuk mengunduh firmware. Platform melacak status pembaruan dan menyimpan riwayat pembaruan dan dapat dipantau proses pembaruan menggunakan dashboard. 


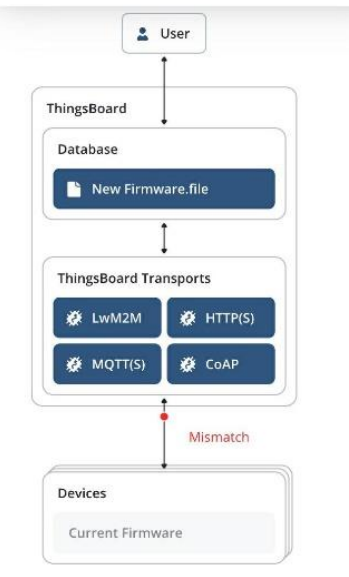

Gambar 2. Desain Framework OTA pada Paltform ThingsBoard

\subsection{Cara kerja On The Air Update (OTA) pada platform ThingsBoard}

Cara melakukan pembaruan On Ther Air (OTA) pada paltform ThingsBoard ini yaitu dengan membuka menu "Pembaruan OTA" pada paltform ThingsBoard untuk mendaftar dan mengunggah paket pembaruan OTA. Paket tersebut terdiri dari judul,versi,profile perangkat, jenis dapat berupa firmware maupun softwa re, a lgoritma checksum dan deskripsi. Untuk melakukan penelusuran paket yang disediakan da pat dicari berdasarkan judul dan mengunduh maupun menghapus paket. Selain itu, log audit juga dapat melacak informasi tentang pengguna yang menyediakan firmware. Menetapkan firmware/perangkat lunak ke profile perangkat berguna untuk mendistribusikan paket secara otomatis ke semua perangkat yang memiliki profile yang sama. Detail profile perangkat akan memungkinkan untuk memilih hanya paket pembaruan OTA yang kompatibel. Versi firmware yang ditetapkan ke perangkat akan secara oto matis menimpa versi firmware yang ditetapkan ke profile perangkat. Penetapan firmware/perangkat lunak ke perangkat atau profil perangkat memicu proses pembaruan. ThingsBoard melacak pembaruan dan mempertahankannya ke atribut perangkat. Pembaruan mungkin memiliki salah satu status berikut. Status pembaruan disimpan sebagaia tribut perangkat dan digunakan untuk memvisualisasikan proses pembaruan pada dashboard. ThingsBoard menyediakan ringkasan pembaruan firmware/perangkat lunak untuk memantau dan melacak status pembaruan firm ware/perangkat lunak perangkat, seperti perangkat mana yang sedang diperbarui saat ini, ma sa lah boot apa pun, dan perangkat mana yang telah diperbarui. Mementau dan melacak status firmware perangkat dapat dilakukan pada dashboard firmware yang a da di latform ThingsBoard.

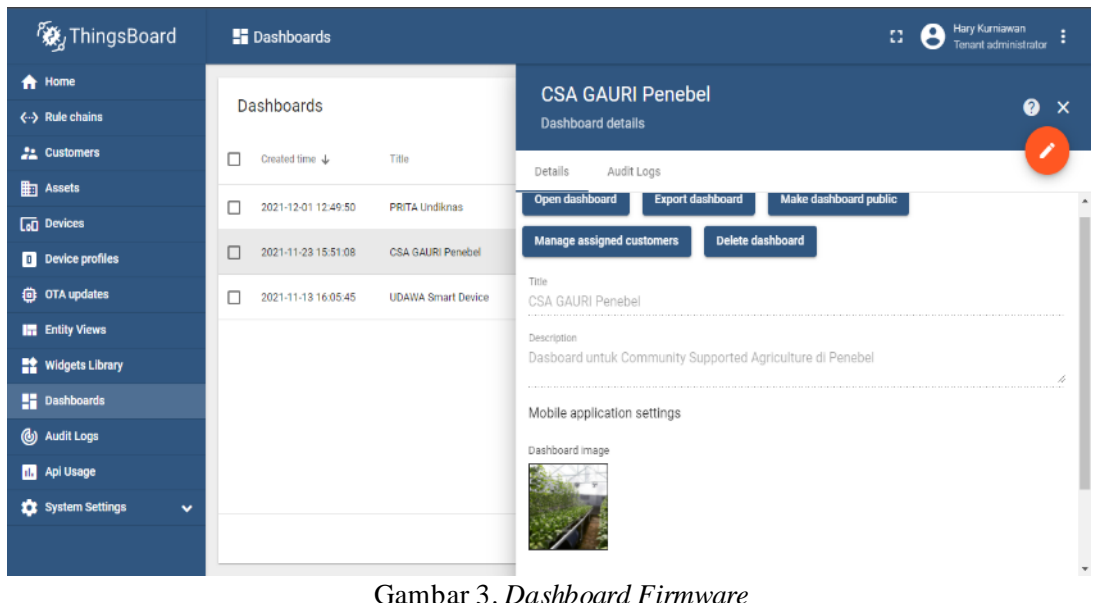

Gambar 3. Dashboard Firmware 


\section{HASIL DAN PEMBAHASAN}

Hasil dari penggunaan fitur Over Ther Air (OTA) pada platform ThingsBoard dalam melakukan pembaharuan firmware pada perangkat Internet of Things(IoT) yang dilakukan tanpa harus datang ke tempat perangkat Internet of Things (IoT) tersebut dan dapat langsung melakukan download dan menginstall sendiri tanpa intervasi manusia.

3.1. Tampilan Fitur On The Air (OTA) pada platform ThingsBoard Ini merupakan tampilan fitur On The Air (OTA) pada platform ThingsBoard.

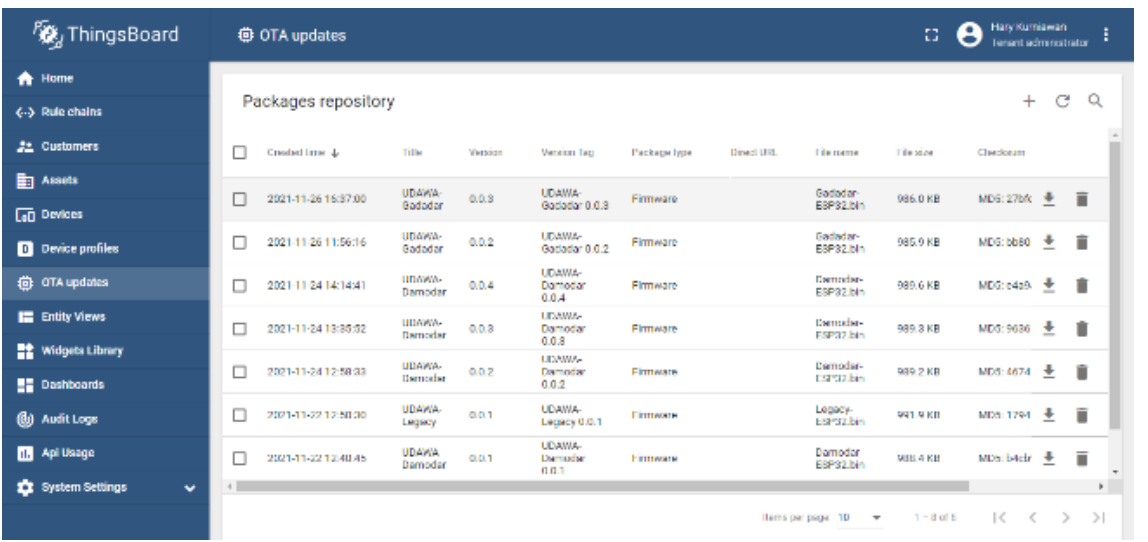

Gambar 4. Tampilan fitur On The Air(OTA)

\subsection{Kelebihan dari Fitur On The Air (OTA) pada platform ThingsBoard}

Kelebihan yang dimiliki fitur On The Air (OTA) ini yaitu dapat melakukan pembaruanfirmware pada sebuah perangkat Internet of Things (IoT) tanpa harus mengambil perangkat Internet of Things(IoT), dan menghubungkan ke komputer menggunakan kabel USB, selanjutnya melakukan update firmware terhadap perangkat Internet of Things(IoT) dan mengembalikan perangkat ke tempat. Dengan adanya fitur pembaruan Over The Air (OTA), pembaruan firm wa re pada perangkat Internet of Things(IoT) dapat dilakukan tanpa hans datang ke tempat perangkat Internet of Things (IoT) tersebut dipasang. Fitur On The Air (OTA) ini dapat mempermudah perusahaan berskala industri yang memiliki perangkat Internet of Things (IoT) di berbagai tempat, jika perusahaan tidak menerapkan fitur On The Air (OTA), maka perusahaan yang memiliki perangkat Internet of Things (IoT) di berbagai tempat akan menghabiskan banyak waktu untuk mendatangi satu persatu tempat perangkat Internet of Things (IoT) dan itu kurang efektif. Fitur On The Air (OTA) ini juga bisa ditemukan pada platform ThingsBoard, dan platform ThingsBoard ini bersifat opensource. Platform ThingsBoard ini bisa digunakan secara gratis maupun berbayartergantung kebutuhan dariproyek Internet of Things(IoT). Bukan hanya itu saja platform Thing sBoard ini dilengkapi sistem kea manan berbasis token akses, MQTT basic credentials, dan Otentika siberbasis sertifikat X.509. Pengguna platform ThingsBoard tidak perlu kha watir akan kehilangan data-data yang ada pada platform ThingsBoard ini.

\subsection{Kekuarangan dariFitur On The Air (OTA) pada platform ThingsBoard}

Meskipun sangat banyak kelebihan On The Air (OTA) bagi pengguna Internet of Things(IoT), akan tetapi pembaruan firmware On The Air (OTA) masih memiliki beberapa kelemahan. On The Air (OTA) membutuhkan perangkat untuk berfungsi dan harus terhubung ke Internet. Selain itu, perangkat harus dimatikan dan dihidupkan ulang untuk menyelesaikan pembaruan, yang dapat menjadi masalah untuk menjadwalkan peningkatannya.

Pembaruan On The Air (OTA) ini juga bisa gagal pada tingkat yang lebih tinggi dari pada pembanuan manual.Secara umum, mendapatkan perangkat lunak untuk memperbarui sendiri adalah masalah yang sulit. Dalam beberapa kasus, file pembaruan akan gagal diunduh ke perangkat jika selama pembaruan perangkat macet atau mati.

\subsection{Keamanan pada platform ThingsBoard}


Platform ThingsBoard memiliki otentikasi berbasis token akses dapat digunakan dalam mode SSL satu arah yang tidak dienkripsi atau mode access token DTLS. Didukung oleh perangkat dengan sumber daya terbatas. Overhead jaringan rendah mudah untuk penyediaan dan penggunaan. Menggunakan MQTT basic credentials, sistem keamanan yang bekerja berdasarkan ID Klien MQTT, nama pengguna, dan kata sandi. Dapat digunakan dalam mode SSL tidak terenkripsi atau satu arah. Selanjutnya platform ThingsBoard menggunakan Otentikasi berbasis sertifikat X.509 digunakan dalam mode SSL dua arah dan CoAP DTLS dengan mode Sertifikat X.509. Tingkat kea manan yang tinggi menggunakan koneksijaringan terenkripsi dan infrastruktur kunci publik.

\section{KESIMPULAN}

Dapat disimpulkan bahwa fitur On The Air update (OTA) pada Internet of Things (IoT) sangat berguna dikarenakan dapat memudahkan pengguna dalam melakukan pembaruan firmware pada sebuah perangkat Internet of Things (IoT) tanpa harus mengambil perangkat Internet of Things(IoT), dan menghubungkan ke komputer menggunakan kabel USB, selanjutny a melakukan update firmware terhadap perangkat Internet of Things(IoT) dan mengembalikan perangkat ke tempat. Khususnya perusahaan berskala industri yang memiliki perangkat Internet of Things(IoT) di berbagaitempat tidak akan menghabiskan banyak waktu lagi untuk mendatangi satu persatu tempat perangkat Internet of Things(IoT) itu dipa sang, karena dengan adanya fitur On The Air update (OTA) ini dapat mempermudah dalam melakukan pembaruan firmawawre tanpa harus datang ke tempat. Fitur On The Air update (OTA) ini bisa ditemukan pada platform ThingsBoard yang bersifat opensource. ThingsBoard ini juga merupakan webserver yang dapat digunakan sebagai platform manajemen device, pengumpulan data, dan visualisasi data berbasis website. Platform ThingsBoard ini dilengkapi sistem keamanan berbasis token akses, MQTT basic credentials, dan Otentikasi berbasis sertifikat X.509. Pengguna platform Thing sBoard tidak perlu khawatir akan kehilangan data-data yang a da pada platform Thing sBoard ini. Kekurangan yang dimiliki oleh fitur On The Air update (OTA) ini yaitu agar perangkat dapat berfungsi, perangkat harus terhubung ke Internet. Selain itu, perangkat harus dimatikan dan dihidupkan ulang untuk menyelesaikan pembaruan, yang dapat menjadi masalah untuk menjadwalkan peningkatannya. Pembaruan On The Air (OTA) ini juga bisa saja menga la mikega galan pada tingkat yang lebih tinggi dari pada melakukan pembaruan secara manual.

\section{DAFTAR RUJUKAN}

[1] Luqman Hakim, Wahyu Andhyka Kusuma, Mahar Faiqurahman, Supriyanto. 2020. "Over The Air Update Firmware pada Perangkat IoT Dengan Protokol MQTT.” Jurnal Sistem dan Informatika (JSI). Vol. 14, No. 2. 2 Mei 2020 : 99105. https://jsi.stikom-bali.ac.id/index.php/jsi/article/view/244

[2] A. S. A. Quadri and B. . O. Sidek. 2014 "An Introduction to Over-the-Air Programming in Wireless Sensor Networks,” Int. J. Comput. Sci. Netw. Solut., vol. $2: 33-49$. https://www.researchgate.net/publication

[3] Matthew Henschke, Xinzhou Wei , Xiaowen Zhang . 2017. "Data Visualization for Wireless Sensor Networks Using ThingsBoard." Wireless and Optical Communications Conference (WOCC). 17 Juni 2020. https://ieeexplore.ieee.org/abstract/document/9114929

[4] Akihiko Kanda , Takashi Kurafuji, Koichi Takeda, Tomoya Ogawa, Yasuhiko Taito, Kazuo Yoshihara, Masaya Nakano, Takashi Ito, Hiroyuki Kondo, and Takashi Kono. 2019. "A 24-MB Embedded Flash System Based on 28nm SG-MONOS Featuring 240-MHz Read Operations and Robust Over-the-Air Software Update for Automotive Applications ". Ieee Solid-State Circuits Letters. Vol. 2, No. 12, december 2019 : 273-276. https://ieeexplore.ieee.org/abstract/document/8879506

[5] Ngo Van Tam, Nguyen Duc Thien. 2020. "Real Time healthcare data visualitation using open source platform ThingsBoard.” Journal of Science. 21 Maret 2020. https://www.researchgate.net/profile/Thien-Nguyen-Duc-2/

[6] ThingsBoard. "Over The Air firmaware and software update." https://thingsboard.io/docs/user-guide/ota-updates/

[7] ThingsBoard. "Device Authentication Options". https://thingsboard.io/docs/user-guide/device-credentials/

[8] D. Evans, "The Internet of Things How the Next Evolution of the Internet Is Changing Everything," 2011 